\title{
A New $\mathrm{Na}^{+}$-Independent Transport System for Dipolar Amino Acids Apparently Corresponding to Systems Persisting after Erythrocyte Maturation in Some Mammalian Genotypes ${ }^{a}$
}

\author{
JAYDUTT V. VADGAMA AND HALVOR N. CHRISTENSEN \\ Department of Biological Chemistry \\ The University of Michigan \\ Ann Arbor, Michigan 48109
}

On the basis of its absence in transport-deficient phenotypes, Young and his associates have discovered in the erythrocytes of sheep and horses a type of $\mathrm{Na}^{+}$-independent transport system that resembles $\mathrm{Na}^{+}$-dependent ASC somewhat in its amino-acid selectivity. These authors have stressed this similarity and accordingly suggested that System ASC might have lost its $\mathrm{Na}^{+}$-dependence in the course of the maturation of the erythrocyte, thus to generate a system of the new type, except in the phenotypes showing the transport-deficient erythrocytes. ${ }^{1,2} \mathrm{We}$ have argued, however, that the cosubstrate $\mathrm{Na}^{+}$plays a decisive role in generating and determining the recognition site of System ASC for the amino acid; hence that system could hardly retain its amino-acid selectivity in the absence of $\mathrm{Na}^{+}{ }^{3}$ We find it more likely that amino-acid binding not only would lose its pattern of selectivity among the amino acids, but would, in the absence of $\mathrm{Na}^{+}$, disappear entirely. Whichever of these alternative possibilities pertains to the life history of this transport system, the mutually accepted provisional designation, System asc, serves to recognize the similarities to System ASC, and by a recently accepted convention, ${ }^{4}$ to take note by its lower case letters of its $\mathrm{Na}^{+}$independence.

In the course of studying the heterogeneity of the $\mathrm{Na}^{+}$-independent uptake of amino acids by the nucleated erythrocyte of the pigeon, we can summarize as follows: (1) These features assist in discriminating the new $\mathrm{Na}^{+}$-independent System asc from the classical System L: (a) The time-courses of the $\mathrm{Na}^{+}$-independent uptake of serine, threonine, cysteine, and alanine are very different (see Fig. 1, in Vadagama and Christensen ${ }^{3}$ ) from the time-courses observed for the uptake of leucine, tryptophan, and the analogue 3-endoaminobicyclo [3.2.1]octane-3-carboxylic acid (BCO). (b) During the 10-minute uptake of threonine, System asc dominates, and leucine and BCO as substrates of System L cause only partial inhibition, whereas threonine, cysteine, serine, and alanine show an apparent tendency to saturate threonine inhibition completely (see Fig. 4 in Vadgama and Christensen ${ }^{3}$ ). These properties allowed us to discriminate for several amino acids their components of transport dominated by the new System asc, or by the classical System L (FIG. 1). (c) System asc was readily inhibited by $N$-ethylmaleimide, whereas System $\mathrm{L}$ is relatively insensitive (FIG. 2).

\footnotetext{
${ }^{a}$ This work was supported by NIH grant HDO 1233 .
} 


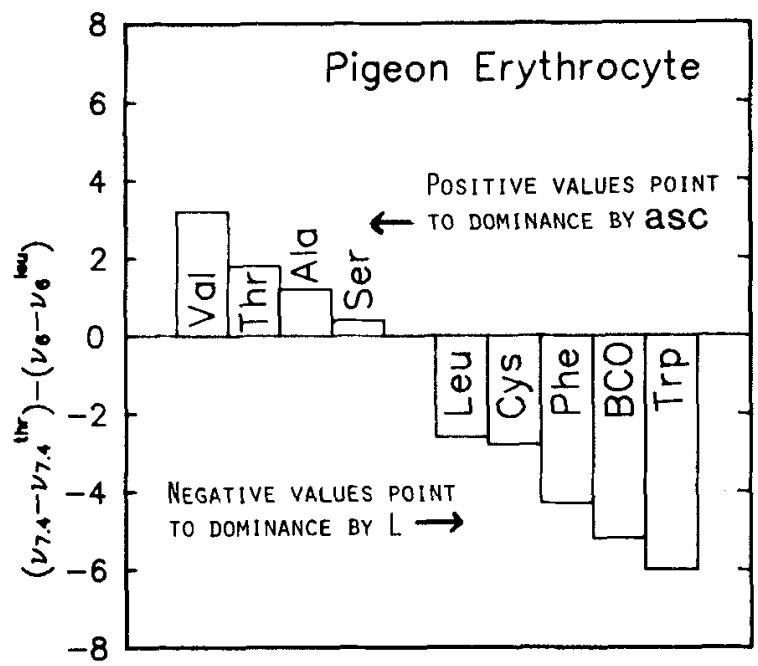

\section{Test Amino Acid $(50 \mu \mathrm{M})$}

FIGURE 1. Discrimination of amino acids transported to substantial degrees by System asc from amino acids more largely transported by System $L$ in the pigeon red cell. The nine amino acids listed were tested as transport substrates at $50 \mu M$, and the sensitivity of their uptake to $20 \mathrm{mM}$ threonine at $\mathrm{pH} 7.4$ and to $20 \mathrm{mM}$ leucine at $\mathrm{pH} 6.0$ noted. The plotting of $\left(\mathrm{v}_{7.4}-\mathrm{v}_{1.4}^{\text {thr }}\right)$ $\left(v_{6}-v_{6}^{\text {leu }}\right)$ estimates the two components above and below the line marked zero. The measures are probably infiuenced by imperfect exclusion of leucine from System asc at $\mathrm{pH}$ 6, and of threonine from System $\mathrm{L}$ at $\mathrm{pH}$ 7.4.

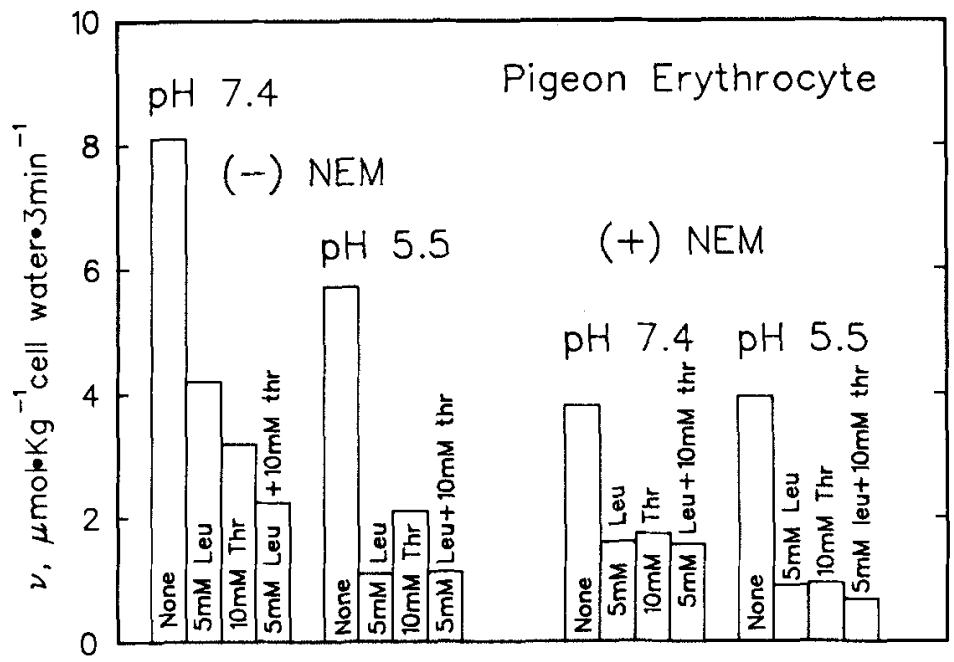

\section{INHIBITOR}

FIGURE 2. Application of $N$-ethylmaleimide further to discriminate threonine uptake by Systems asc and L. Pigeon erythrocytes were incubated for 15 minutes in choline-KRP, pH 7.4 at $37^{\circ} \mathrm{C}$ in the absence or presence of $2 \mathrm{mMN} N$-ethylmaleimide. The uptake of $50 \mu M \mathrm{~L}$ $\left[{ }^{3} \mathrm{H}\right]$ threonine was measured for three minutes at $\mathrm{pH} 7.4$ or 5.5 in the presence of the indicated inhibitor. 
(2) Similarities between the $\mathrm{Na}^{+}$-independent System asc and the $\mathrm{Na}^{+}$-dependent System ASC: (a) Preference for threonine, serine, alanine and perhaps cysteine; (b) strong mutual inhibition by these preferred substrates in both systems; (c) a decline in activity on lowering the $\mathrm{pH}$, not however at the same $\mathrm{pH}$ range; and (d) both are highly sensitive to inhibition by NEM.

(3) Aspects in which $\mathrm{Na}^{+}$-independent System asc differs from System ASC: (a) asc shows a pH profile that peaks at 7.5 (Fig. 5B, in Vadgama and Christensen ${ }^{3}$ ), while ASC peaks at 6.0 (Fig. 1, in Vadgama and Christensen ${ }^{5}$ ). (b) Cysteine sulfinate shows little inhibition of $\mathrm{Na}^{+}$-independent threonine uptake in the $\mathrm{pH}$ range 7 to 5 , a range in which System ASC shows increasing sensitivity to this anionic analogue. ${ }^{5}$ (c) In contrast to ASC, $\mathrm{Na}^{+}$-independent asc fails to interact with the dibasic amino acids, lysine, ornithine, and 2,4-diaminobutyrate. (d) System asc shows no interaction with the prolines, whereas ASC reacts strongly with hydroxyproline. ${ }^{6}$

The nucleated avian red blood cell is analogous to equivalent precursor cells arising in the differentiation of the mammalian red blood cell. Our results indicate that the new $\mathrm{Na}^{+}$-independent System asc is probably a significant biological entity and not merely a product of terminal mammalian red cell differentiation.

\section{REFERENCES}

1. YounG, J. D., J. C. Ellory \& E. M. TuCKer. 1975. Nature (London) 254: 156-157.

2. Fincham, D. A., D. K. MASON \& J. D. Young. 1985. Biochem. J. 227: 13-20.

3. Vadgama, J. V. \& H. N. Christensen. 1985. J. Biol. Chem. 260; 2912-2921.

4. Bannal, S., H. N. Christensen, J. V. Vadgama, J. C. Ellory, E. Englesberg, G. G. Guidotti, G. C. Gazzola, M. S. Kilberg, A. Lajtha, B. Sacktor, F. V. Sepúllveda, J. D. YouNG, D. YUdilevich \& G. MANN. 1984. Nature 311: 308.

5. Vadgama, J. V. \& H. N. Christensen. 1984. J. Biol. Chem. 259: 3648-3652.

6. Thomas, E. L. \& H. N. Christensen. 1971. J. Biol. Chem. 246: 1682-1688. 